\title{
HYDRODYNAMIC BEHAVIOR OF DISPERSED PHASE IN A SPRAY COLUMN WITH AN ELECTRIC FIELD FOR LIOUID-LIOUID EXTRACTION
}

\author{
MANABU YAMAGUCHI, HIROYUKI SUGAYA \\ AND TAKASHI KATAYAMA \\ Department of Chemical Engineering, Osaka University, Toyonaka 560
}

Key Words: Fluid Mechanics, Electric Field, Drop Size Distribution, Drop Velocity, Electrostatic

Coalescence Dispersion, Dispersed Phase Holdup, Liquid Liquid Extraction

\begin{abstract}
A new spray column with vertical four-pole electrodes is developed for use as an electrostatic liquid extractor. The population behavior of dispersed drops in a d.c. electric field is studied in terms of dispersed-phase holdup, drop velocity, drop size distribution by use of the system of water drops in cyclohexane. It is found that the holdup characteristic, drop velocity and drop volume can be easily controlled by changing the strength of electric field in the two-phase flow contactor.
\end{abstract}

\section{Introduction}

An effective dispersion of one liquid phase into the other is one of the important factors determining performance efficiency of a liquid-liquid extractor. Therefore, techniques for drop dispersion have been devised by many researchers. ${ }^{1,2,4,5,10)}$ Recently, novel equipment for liquid dispersion by a d.c. electrostatic force was developed. ${ }^{10)}$ It was shown qualitatively that the equipment had some favorable characteristics for liquid dispersion, mixing of the liquid phases, and phase separation, but the holdup of the dispersed phase was low. In the present study, a spray column equipped with a d.c. electric field was designed in order to increase the holdup of the dispersed phase. The electro-hydrodynamics (moving velocity and size distribution of the drops) and the holdup characteristics in the column were investigated.

\section{Experimental}

\subsection{Experimental apparatus}

Figure 1 shows a schematic diagram of the experimental apparatus. The test column, $90 \mathrm{~mm}$ inner dia. and $300 \mathrm{~mm}$ high, was made of transparent acrylic resin for observation of the dispersed phase. Four electrodes, copper rods $5 \mathrm{~mm}$ in dia. and $300 \mathrm{~mm}$ long, were installed vertically along the inner wall of the column and were spaced at equal intervals (see Section B-B in Fig. 1). The arrangement of the electrodes and their shape influenced the electrohydrodynamic behavior of the drops, such as coalescence, redispersion and motion of the drops. The rod elec-

\footnotetext{
Received July 2, 1987. Correspondence concerning this article should be addressed to
} T. Katayama. H. Sugaya is now with Toray Ind., Inc., Ohtsu 520 trodes (4) were connected to a high-voltage d.c. generator (Brandenburg 2807R) (15). The other electrodes (5) were grounded through an electrometer (Takeda Riken TR8651) (16) for measurement of the electric current between the electrodes. The upper part of the column (2) was removable and was equipped with a distributor (1) having 31 pieces of stainless hypodermic tubing $(0.3 \mathrm{~mm}$ i.d. $)$ for supply of disper-

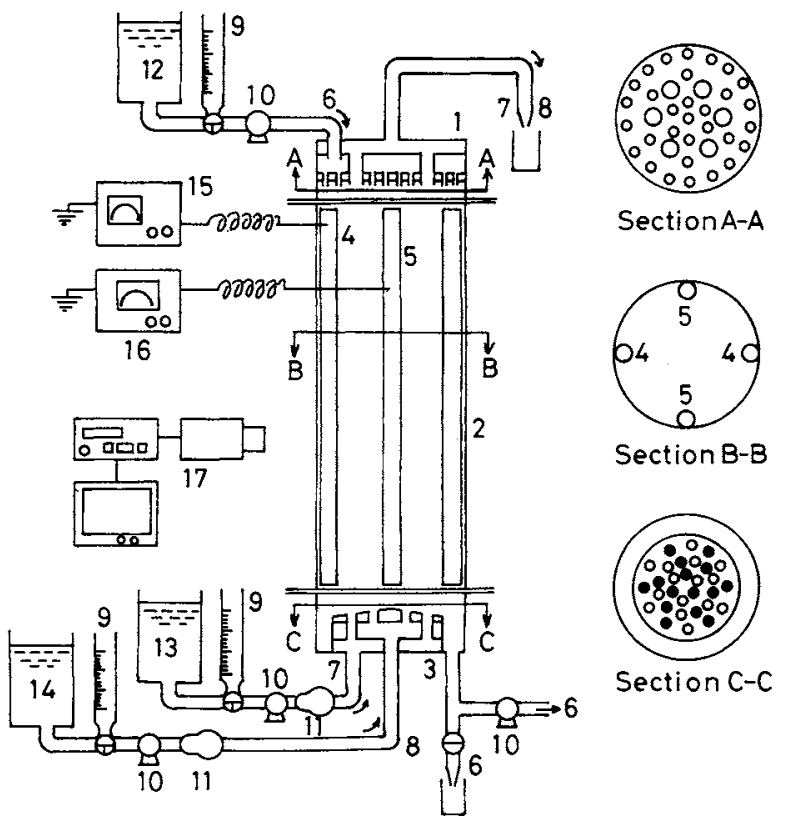

Fig. 1. Schematic diagram of experimental apparatus 1 , distributor of dispersed phase; 2, spray column with electrodes; 3, distributor of continuous (tracer) phase; 4, 5, copper rod electrode; 6 , inlet and outlet of dispersed phase; 7 , 8 , inlet and outlet of continuous (tracer) phase; 9 , burette; 10 , roller pump; 11, air damper; 12, 13, 14, liquid reservoir; 15, high-voltage d.c. unit; 16 , electrometer; $17, T . V$. system 
Table 1. Physical properties of liquids used at $20^{\circ} \mathrm{C}$

\begin{tabular}{lccccc}
\hline & $\begin{array}{c}\text { Density } \\
{\left[\mathrm{kg} / \mathrm{m}^{3}\right]}\end{array}$ & $\begin{array}{c}\text { Interfacial } \\
\text { tension } \\
{[\mathrm{mN} / \mathrm{m}]}\end{array}$ & $\begin{array}{c}\text { Viscosity } \\
{[\mathrm{mPa} \cdot \mathrm{s}]}\end{array}$ & $\begin{array}{c}\text { Dielectric } \\
\text { constant } \\
{[-]}\end{array}$ & $\begin{array}{c}\text { Electric } \\
\text { conductivity } \\
{[\mathrm{S} / \mathrm{m}]}\end{array}$ \\
\hline Water & 998 & - & 1.00 & 80.1 & $10^{-6}$ \\
Cyclohexane & 770 & 48.0 & 0.98 & 2.02 & $10^{-16}$ \\
\hline
\end{tabular}

sed phase (small circles in Section A-A in Fig. 1) and with outlets for continuous phase (large circles in Section A-A). The lower part of the column was also removable and was equipped with a distributor (3) having two sets of 15 holes ( $3 \mathrm{~mm}$ dia.) each for supply of the continuous phase and a tracer liquid phase, respectively (see Section C-C in Fig. 1), and with an outlet for the dispersed phase (6). Arrangement of the distributor holes was devised to feed the continuous liquid phase uniformly into the column. The upper and lower parts are exchangeable with each other when the density of the dispersed phase is lighter than that of the continuous phase. When the holdup of the dispersed phase was measured, the lower part was exchanged with a phase collector. The physical properties of liquids used are listed in Table 1.

\subsection{Experimental procedure}

The column was filled with cyclohexane as continuous phase and the liquid was kept stagnant during the experiment. Deionized water as dispersed phase was fed from the top through the distributor to the column by a roller pump (Cole-Parmer) (10) and a given voltage was applied. After a steady-state flow of dispersed phase was maintained at the applied voltage, the feeding of the phase was stopped and simultaneously the voltage was set at zero value. The holdup was determined by measuring the volume of the dispersed phase settled in the collector. The moving velocity and size of the drops were recorded by a camera and $\mathrm{T}$. V. system (17). The recording was performed for the $12-\mathrm{cm}$ vertical distance between the points $10 \mathrm{~cm}$ and $22 \mathrm{~cm}$ below the nozzle tip. The drop velocity was analyzed by the same method as was described in the previous paper. ${ }^{93}$ The drop size was determined by measuring the drop profiles recorded in photographs.

\section{Results and Discussion}

\subsection{Motion of drops in the electric field}

The arrangement of four-pole electrodes in the column produces complex profiles of electrical potential (see Fig. 2). ${ }^{7}$ In the absence of the electric field, the water drops formed at the distributor fell straight without coalescence between the drops. In the presence of the electric field, they were attracted toward the electrodes by dielectrophoretic force and received

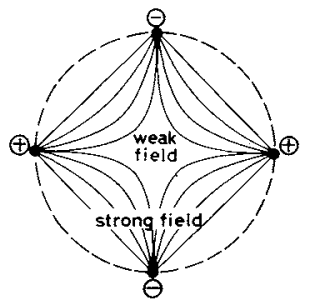

Fig. 2. Arrangement of four-pole electrodes and electric force lines

electric charge after contacting the electrodes. In a low fraction of the dispersed-phase holdup, the frequency of electrical coalescence between the drops was very low irrespective of the voltage applied. The drops fell with zigzag and spiral motion caused by the Coulomb force as the interaction of the drop charge with the electric field. However, when the holdup was increased with the feed rate of dispersed phase, electrical coalescence and redispersion of the drops became active. The coalescence occurred between charged drops or between charged and uncharged drops according to the Coulomb force. The redispersion occurred according to the Maxwell electrical stress: increasing a nonuniform electrostatic force opposed to the interfacial one all over the surface of the drop promotes drop formation, and the drop then splits into several drops when the former force overcomes the latter. The behavior of coalescence and redispersion was easily controlled by changing the strength of the electric field. This means that the field strength, like the shear flow stress produced by the agitator in an agitated vessel, is an important factor in controlling the motion, size and residence time of the drops.

The falling velocity of the drops was estimated as follows. The components of force acting on a charged drop in the electric field and those of velocity of the drop are shown in Fig. 3 and their relations are given by Eq. (1),

$$
F_{\mathrm{t}}=\left(F_{\mathrm{e}}^{2}+F_{\mathrm{g}}^{2}\right)^{1 / 2}, \quad U_{\mathrm{z}}=U_{\mathrm{t}} \times \frac{F_{\mathrm{g}}}{F_{\mathrm{t}}}
$$

As the drop velocity is subjected to Allen's law or Newton's law according to its Reynolds number, the respective drop velocities are given by the following equations:

for Allen's law region $(6<\operatorname{Re}<516)$ 


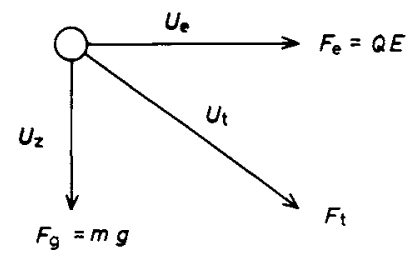

Fig. 3. Force components acting on a charged drop and its velocity components

$$
U_{\mathrm{t}}=\left(\frac{16 F_{\mathrm{t}}^{2}}{25 \rho_{\mathrm{c}} \mu_{\mathrm{c}} \pi^{2} d_{\mathrm{e}}^{3}}\right)^{1 / 3}
$$

for Newton's law region $(R e>516)$

$$
U_{\mathrm{t}}=\left(\frac{200 F_{\mathrm{t}}}{11 \pi \rho_{\mathrm{c}} d_{\mathrm{e}}^{2}}\right)^{1 / 2}
$$

The electric force in Eq. (1) was evaluated as follows. The moving drops in the present study were divided into the following four groups: 1) drops colliding with the electrodes and bouncing back while maintaining drop volume, 2) drops newly produced by the electric force from water drops adhering to the electrodes, 3) drops coalesced from the drops falling in the electric field, and 4) coalesced drops that were redispersed during their motion. The drops of types 1) and 2) were assumed to receive electric charges given by Eq. (4), ${ }^{8)}$ because their charges were determined by

$$
Q=0.776 \pi \varepsilon_{\mathrm{c}} \varepsilon_{0} d_{\mathrm{e}}\left(1+\frac{d_{\mathrm{e}}}{4 l}\right) E_{\mathrm{p}}
$$

by the electrical potential of the electrodes which the drops contacted. The maximum strength of the electric field to which the drops were subjected was evaluated at the shortest distance between the electrodes. Therefore, the maximum value of the electric force acting on the drops in Eq. (1) is given by Eq. (5).

$$
F_{\mathrm{e}}=Q E=0.776 \pi \varepsilon_{\mathrm{c}} \varepsilon_{0} d_{\mathrm{e}}\left(1+\frac{d_{\mathrm{e}}}{4 l}\right) E_{\mathrm{p}} \frac{E_{\mathrm{p}}}{l}
$$

The falling velocity $\left(U_{z}\right)$ is derived by Eqs. (1)-(5) as follows.

for Allen's law region

$$
\begin{aligned}
U_{\mathrm{z}}= & \left(\rho_{\mathrm{d}}-\rho_{\mathrm{c}}\right) d_{\mathrm{e}}^{2} g\left(\frac{2 \pi}{675 \rho_{\mathrm{c}} \mu_{\mathrm{c}}}\right)^{1 / 3} \\
& \times\left\{0.771 \pi^{2} \varepsilon_{\mathrm{c}}^{2} \varepsilon_{0}^{2} d_{\mathrm{e}}^{2}\left(1+\frac{d_{\mathrm{e}}}{4 l}\right)^{2} \frac{E_{\mathrm{p}}^{4}}{l^{2}}\right. \\
& \left.+\frac{\pi^{2}}{36}\left(\rho_{\mathrm{d}}-\rho_{\mathrm{c}}\right)^{2} g^{2} d_{\mathrm{e}}^{6}\right\}^{-1 / 6}
\end{aligned}
$$

for Newton's law region

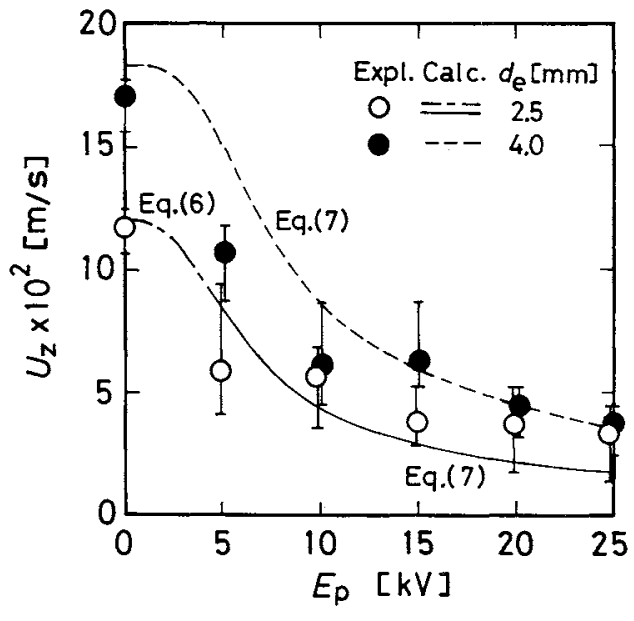

Fig. 4. Applied voltage versus moving velocity of uncharged and charged drops falling through cyclohexane

$$
\begin{aligned}
U_{\mathrm{z}}= & \left(\rho_{\mathrm{d}}-\rho_{\mathrm{c}}\right) d_{\mathrm{e}}^{2} g\left(\frac{50 \pi}{99 \rho_{\mathrm{c}}}\right)^{1 / 2} \\
& \times\left\{0.771 \pi^{2} \varepsilon_{\mathrm{c}}^{2} \varepsilon_{0}^{2} d_{\mathrm{e}}^{2}\left(1+\frac{d_{\mathrm{e}}}{4 l}\right)^{2} \frac{E_{\mathrm{p}}^{4}}{l^{2}}\right. \\
& \left.+\frac{\pi^{2}}{36}\left(\rho_{\mathrm{d}}-\rho_{\mathrm{c}}\right)^{2} g^{2} d_{\mathrm{e}}^{6}\right\}^{-1 / 4}
\end{aligned}
$$

where $l=5.5 \mathrm{~cm}$. The values calculated by Eqs. (6) and (7) are the lowest ones in the electric field. Examples of the experimental results are shown in Fig. 4, in which the falling velocity $\left(U_{z}\right)$ is plotted against the applied voltage for drop sizes of $d_{\mathrm{e}}=2.5$ and $4.0 \mathrm{~mm}$. The open and solid symbols show experimental velocities of single drops in the presence of an ensemble of the drops, and the vertical bar skewering the symbols indicates the range of experimental data. The chain and solid lines for $d_{\mathrm{e}}=2.5 \mathrm{~mm}$ are the values calculated by Eqs. (6) and (7), and the dotted line for $d_{\mathrm{e}}=4.0 \mathrm{~mm}$ is the value by Eq. (7). They are in agreement with the experimental data. Both the experimental and calculated velocities decreased markedly with increase of the applied voltage. The decrease of the falling velocity $\left(U_{\mathrm{z}}\right)$ is due to the increase in the horizontal velocity component $\left(U_{\mathrm{e}}\right)$ with the voltage. This makes the residence time of the drops increase and hence produces an increase of the dispersed-phase holdup.

\subsection{Drop size distribution}

A typical size distribution for uncharged drops is presented in Fig. 5a $\left(E_{\mathrm{p}}=0 \mathrm{kV}\right)$ and that for charged drops in Fig. 5b $\left(E_{\mathrm{p}}=25 \mathrm{kV}\right)$. In the figures the volumetric distribution density of the drops is plotted against drop size with applied voltage as a parameter. The solid line in each figure is the value calculated by the Mugele-Evans distribution function, ${ }^{6}$ ) which is given by the following equation: 

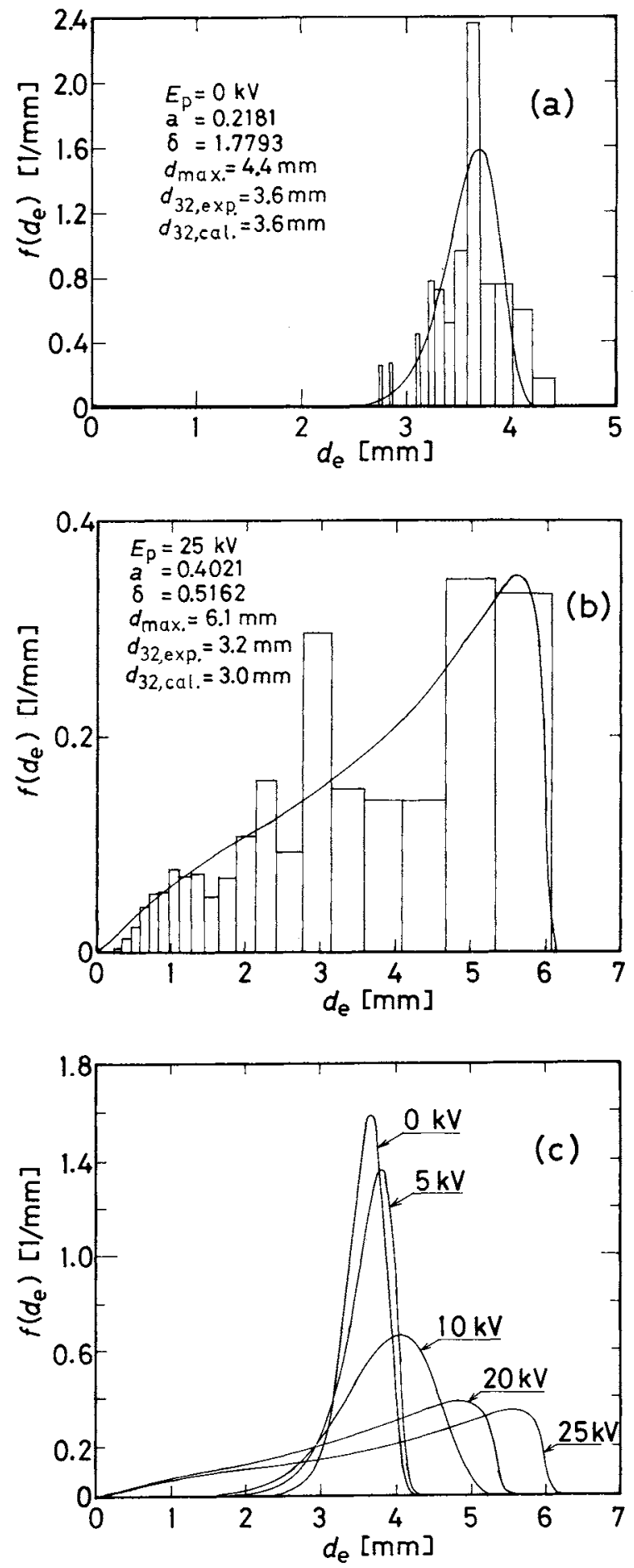

Fig. 5. Effect of applied voltage on drop size distribution $\left(\widetilde{U}_{\mathrm{d}}=2.9 \times 10^{-4} \mathrm{~m} / \mathrm{s}\right)$

$$
f\left(d_{\mathrm{e}}\right)=\frac{\delta}{\sqrt{\pi}} \frac{d_{\max }}{d_{\mathrm{e}}\left(d_{\max }-d_{\mathrm{e}}\right)} \exp \left\{-\left(\delta \ln \frac{a d_{\mathrm{e}}}{d_{\max }-d_{\mathrm{e}}}\right)^{2}\right\}
$$

The parameters in the equation were determined by the method of least-squares so as to fit experimental data. It was shown by Cruz-Pinto and Korchinsky ${ }^{3)}$ that Eq. (8) expressed satisfactorily the drop size distribution in a rotating disk column. Profiles of all

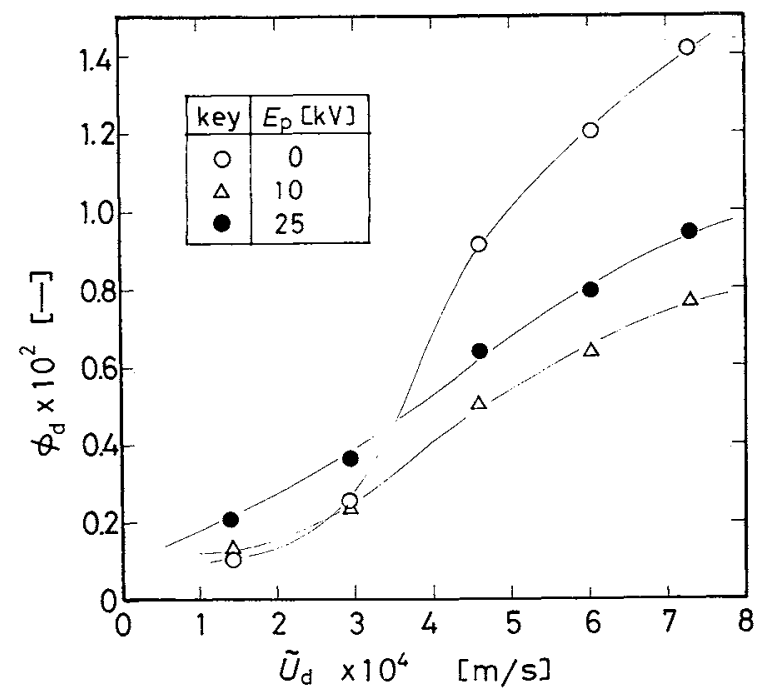

Fig. 6. Effect of feed rate of dispersed phase on holdup fraction for various applied voltages

the experimental drop size distributions determined by Eq. (8) are shown in Fig. $\mathbf{5 c}$ for various applied voltages. The distribution curves are wider with increase of the applied voltage, but the wider distribution is not favorable in an actual extractor.

\subsection{Holdup fraction of the dispersed phase}

In Fig. 6, experimental holdup is plotted against the feed rate of the dispersed phase for applied voltages of 0,10 and $25 \mathrm{kV}$. As shown in the figure, when the feed rate was low (e.g., $\widetilde{U}_{\mathrm{d}}=1.42 \times 10^{-4} \mathrm{~m} / \mathrm{s}$ ), the holdup increased with the applied voltage. As mentioned in Section 2.1, this is because zigzag and spiral motion of the drops increases their residence time. On the other hand, when the feed rate was more than $3 \times 10^{-4} \mathrm{~m} / \mathrm{s}$, the effect of the applied voltage on the holdup was different from that in the low feed rate. That is, with increasing applied voltage the holdup first decreased and then began to increase. This is due to the following reason. At a low voltage, electrical coalescence between the falling drops occurred because of the increase in holdup with feed rate, but the electric field was not strong enough to redisperse the drops; thus coalescence was favored. The drops became much larger and their velocities $\left(U_{z}\right)$ increased. Consequently, the residence time decreased and the holdup also decreased. At a high voltage, the electric field was stronger and the electrical coalescence and redispersion of the drops became active, decreasing the volumes and velocities $\left(U_{z}\right)$ of the drops. As a result, the residence time of the drops increased and the holdup also increased. However, the holdup in the presence of the electric field was lower than that in its absence. This is because the presence of a weak electric field as shown in Fig. 2 could not produce a desirable redispersion. The geometry of the electrodes should be further modified so as to obtain higher 
holdup than that in the absence of the electric field.

\section{Conclusions}

The behavior of an ensemble of water drops in cyclohexane under the influence of a d.c. electric field was studied in a newly constructed liquid-liquid extractor. Hydrodynamic characteristics obtained were as follows.

1) At low holdup of dispersed phase, the moving velocity of the drops in an ensemble of drops is not influenced markedly by other drops and can be estimated satisfactorily by a semi-empirical equation for single-drop velocity.

2) The coalescence-redispersion behavior of the drops in the upper zone in the column is different from that in the lower one.

3) The size distribution profile of the drops tends to become wider with increase of the voltage applied.

4) The holdup characteristics of the dispersed phase depend significantly on both the feed rate of the dispersed phase and the strength of the applied electric field.

\section{Acknowledgment}

This work was supported by a Grant-in-Aid for Energy Research (2) (Projects No. 60045074 and 61040052) from the Ministry of Education, Science and Culture of Japan.

\section{Nomenclature}

$\begin{array}{ll}a & =\text { asymmetrical distribution parameter } \\ d_{\mathrm{e}} & =\text { equivalent spherical drop diameter } \\ d_{\max } & =\text { maximum diameter of drop } \\ E & =\text { electric field strength } \\ E_{\mathrm{p}} & =\text { applied voltage } \\ f\left(d_{\mathrm{e}}\right) & =\text { volumetric distribution density of drop } \\ F_{\mathrm{e}} & =\text { electric force acting on drop }\end{array}$

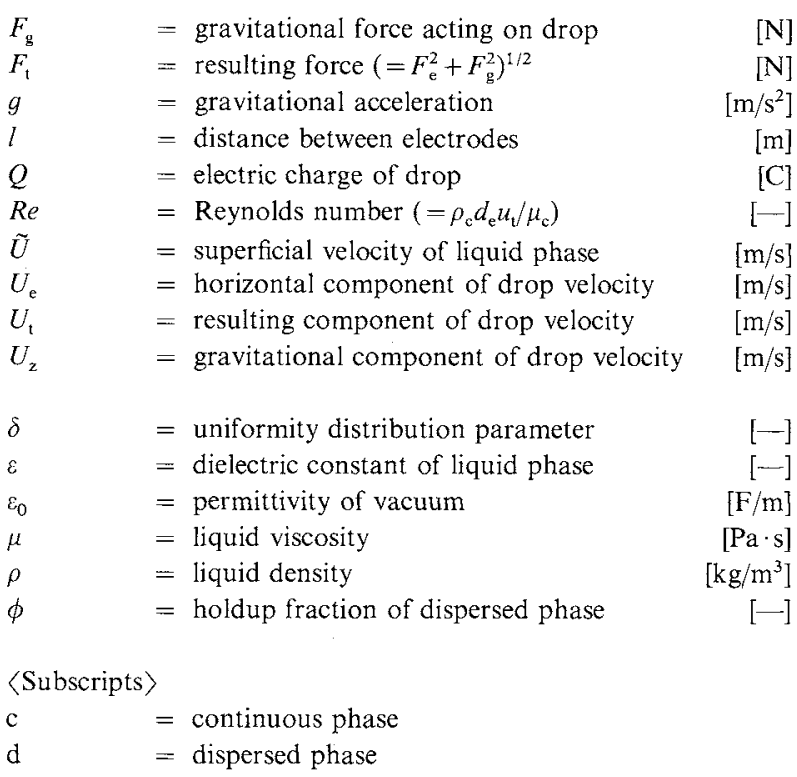

\section{Literature Cited}

1) Agaiev, A. A. and P. Ch. Abdullaev: Izv. V. U. Z. Neft $i$ Gas, 3, 53 (1969).

2) Bailes, P. J. and J. D. Thornton: Proc. ISEC, p. 1011 (1974).

3) Cruz-Pinto, J. J. C. and W. J. Korchisky: Chem. Eng. Sci., 35, $2213(1980)$.

4) Kowalski, W. and Z. Ziolkowski: Intl. Chem. Eng., 21, 323 (1981).

5) Martin, L. and P. Vignet: Sep. Sci. and Tech., 18, 1455 (1983).

6) Mugele, R. A. and H. D. Evans: IEC, 43, 1317 (1951).

7) Pohl, H. A.: "Dielectrophoresis," p. 470, Cambridge University Press (1978).

8) Takamatsu, T., M. Yamaguchi and T. Katayama: J. Chem. Eng. Japan, 16, 267 (1983).

9) Takamatsu, T., M. Yamaguchi and T. Katayama: J. Chem. Eng. Japan, 16, 324 (1983).

10) Yoshida, F., M. Yamaguchi and T. Katayama: J. Chem. Eng. Japan, 19, 1 (1986). 